\title{
MEDIA PEMBELAJARAN INTERAKTIF BERBASIS FITUR MIND MAP
}

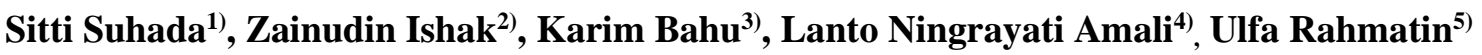 \\ ${ }^{1,2,3,5)}$ Program Studi Pendidikan Teknologi Informasi, Fakultas Teknik, Universitas Negeri Gorontalo \\ 4) Program Studi Sistem Informasi, Fakultas Teknik, Universitas Negeri Gorontalo \\ Email: ningrayati_amali@ung.ac.id ${ }^{4)}$ \\ Asal Negara: Indonesia
}

\begin{abstract}
ABSTRAK
Media pembelajaran berfungsi sebagai pendorong motivasi siswa untuk belajar dan mempertinggi daya serap siswa. Penelitian ini bertujuan untuk merancang media pembelajaran dengan fitur mind map. Penelitian dilakukan di SMK Negeri 5 Gorontalo dengan subjek penelitian adalah siswa kelas x jurusan teknik komputer jaringan pada mata pelajaran komputer dan jaringan dasar. Metode penelitian yang digunakan adalah Research and Development (R\&D) model pembelajaran ADDIE dengan tahapan adalah analisis, desain, pembangunan, implementasi, dan evaluasi. Data dikumpulkan dengan melakukan wawancara, observasi serta angket penilaian dari ahli materi, ahli media dan pengguna (siswa). Hasil penelitian menunjukkan bahwa presentase kelayakan media pembelajaran menurut ahli materi sebesar 96\%, presentase kelayakan menurut ahli media sebesar $91 \%$ serta respon pengguna sebesar $96.45 \%$. Produk berupa media pembelajaran dengan fitur mind map pada mata pelajaran Komputer dan Jaringan Dasar ini memiliki tingkat validitas kelayakan yang tinggi sesuai penilaian para ahli dan dinyatakan sangat layak untuk digunakan pada pembelajaran komputer dan jaringan dasar.
\end{abstract}

Kata kunci: Media pembelajaran; fitur mind map; interaktif; komputer dan jaringan dasar; ADDIE

\section{ABSTRACT}

Learning media serves as a motivational driver for students to learn and increase student absorption. This research aims to design learning media with mind map features. The research was conducted at SMK Negeri 5 Gorontalo with the subject of research is grade $x$ students majoring in computer engineering network in basic computer and network subjects. The research method used is research and development (R\&D) of ADDIE learning model with stages is analysis, design, development, implementation, and evaluation. Data is collected by conducting interviews, observations and assessment questionnaires from material experts, media experts and users (students). The results showed that the percentage of the feasibility of learning media according to the material expert was $96 \%$, the percentage of eligibility according to media experts was $91 \%$ and the user response was $96.45 \%$. This product in the form of learning media with mind map features in computer subjects and basic network has a high level of validity according to the assessment of experts and is declared very feasible to use in basic computer and network learning.

Keywords: Learning Media; mind map feature; interactive; basic computers and networks; ADDIE

\section{PENDAHULUAN}

Media dapat merangsang siswa untuk belajar yang terdiri dari berbagai jenis komponen dalam lingkungan siswa (Sadiman, 2014). Menurut Gerlach \& Ely (dalam Anggereni dan Khairurradzikin, 2016) bahwa media membangun kondisi yang membuat siswa mampu memperoleh pengetahuan, keterampilan, atau sikap yang dapat berupa materi atau kejadian. Adapun Briggs (dalam Arsyad, 2014) berpendapat bahwa media dapat berupa buku, film, kaset, dan film bingkai sebagai alat fisik yang dapat menyajikan pesan dan merangsang siswa untuk belajar. Dalam konteks pembelajaran media sebagai bagian integral pembelajaran yang perlu mendapat perhatian.

Dalam proses belajar mengajar yang terpenting adalah menentukan ketercapaian tujuan belajar dan hal ini ditandai dengan perubahan tingkah laku baik dari segi pengetahuan (kognitif), keterampilan (psikomotor), maupun nilai sikap (afektif). Faktor yang mempengaruhi tercapainya tujuan pembelajaran ini salah satunya adalah media pembelajaran. Permasalahan dalam pembelajaran yang sering terjadi selama ini adalah proses pengajaran berjalan dan berlangsung tidak efektif dan tujuan belajar tidak dapat tercapai bahkan tidak terjadi proses komunikasi antara guru dan siswa. Hal inipun sesuai kondisi yang terjadi di SMK Negeri 5 Gorontalo.

Berdasarkan hasil observasi dan wawancara dengan guru maupun siswa pada mata pelajaran komputer dan jaringan dasar, terlihat bahwa penggunaan media pembelajaran hanya berupa media presentasi PowerPoint yang lebih banyak memunculkan salinan materi tanpa terlihat interaksi didalamnya. Akibatnya siswa menjadi kurang fokus terhadap materi yang disampaikan dan cenderung jenuh dan kurang memperhatikan pada saat proses 
pembelajaran sedang berlangsung. Hal ini menyebabkan hasil belajar siswa menjadi rendah dimana persentase nilai siswa pada mata pelajaran ini hanya $45 \%$ yang memenuhi kriteria ketuntasan minimal (KKM) yang di tentukan sekolah yakni 75 .

Salah satu upaya yang dapat dilakukan untuk membantu siswa dalam proses penerimaan materi adalah dengan menggunakan media pembelajaran. Penggunaan media dalam dunia pembelajaran sangat dibutuhkan untuk membangkitkan semangat siswa dalam belajar, sebagaimana yang diungkap oleh Hamalik (dalam Suryani, 2016) bahwa media pembelajaran dapat membangkitkan motivasi dan rangsangan kegiatan belajar, minat dan gairah yang baru, dan membawa pengaruh psikologis terhadap siswa. Gagne (1985) menyatakan bahwa media pembelajaran adalah berbagai jenis komponen dalam lingkungan siswa yang dapat merangsangnya untuk belajar. Adapun Suryani (2017) menyatakan bahwa media pembelajaran dapat membantu siswa menyajikan data dengan menarik dan terpercaya, memadatkan penyajian data, mepermudah penafsiran, sehingga dapat meningkatkan pemahaman siswa.

Perancangan media pembelajaran perlu dirancang secara sistematis dan memberdayakan teknologi pembelajaran dan media pembelajaran di kelas. Kondisi ini perlu adanya komitmen para guru yang lebih menekankan pada pemberdayaan teknologi pembelajaran dan media pembelajaran. Perancangan media pembelajaran ini dapat membantu, guru membawa dunia luar ke dalam kelas, dimana ide yang abstrak dan asing (metode) sifatnya menjadi konkrit dan mudah dimengerti oleh siswa. Dengan demikian jika alat/media pembelajaran dapat difungsikan secara tepat dan profesional, maka proses pembelajaran akan berjalan efektif. Guru hendaknya mampu berinovasi dan berkreasi dalam rangka merancang suatu pembelajaran yang menarik dan bermakna bagi siswa.

Oleh karena itu penggunaan teknologi, khususnya media pembelajaran dapat digunakan guru untuk membantu memfasilitasi pembelajaran siswa. Belajar dengan teknologi telah menjadi hal yang penting di sekolah masa kini. Di seluruh dunia, baik pemerintah, sistem pendidikan, peneliti, guru, dan orang tua menganggap teknologi sebagai bagian penting dari pendidikan (Eady, 2013). Teknologi, selalu menjadi bagian dari lingkungan belajar dan mengajar serta merupakan bagian dari kotak alat profesional guru. Dengan kata lain, sebagai sumber yang digunakan guru untuk membantu memfasilitasi pembelajaran siswa.

Menurut Rusman (2013), program pembelajaran yang digunakan dalam proses pembelajaran dengan menggunakan software komputer berupa program komputer yang berisi materi pelajaran dalam bentuk latihan-latihan merupakan program pembelajaran berbasis komputer. Melalui pembelajaran ini bahan ajar disajikan melalui media komputer sehingga proses belajar mengajar menjadi lebih menarik bagi siswa dengan rancangan pembelajaran yang bersifat interaktif. Dengan kata lain, pendekatan menggunakan teknologi digital sebagai media pembelajaran memiliki dampak yang lebih baik dan lebih efektif daripada yang lain (Amali, dkk, 2020). Pembelajaran berbasis komputer menggunakan program pembelajaran dengan menggunakan software berupa program komputer yang berisi bahan-bahan pembelajaran akan mudah dipahami.

Di sisi lain media pelajaran yang berbasis komputer perlu penyajian secara interaktif agar lebih menarik. Mustholiq (dalam Pramuaji dan Munir, 2017) berpendapat bahwa tujuan penggunaan media interaktif adalah membuat peserta didik mampu mengembangkan pengetahuannya mengenai yang telah dipelajari. Media pembelajaran interaktif merupakan bahan ajar yang mengkombinasikan beberapa media pembelajaran audio, video, teks, grafik, dan animasi. Adapun menurut Saputra (2013) media pembelajaran interaktif adalah suatu sistem penyampaian pengajaran yang menyajikan materi video rekaman dengan pengendalian komputer kepada siswa yang tidak hanya mendengar dan melihat video dan suara, tetapi juga memberikan respon yang aktif, dan respon itu yang menentukan kecepatan dan sekuensi penyajian. Media interaktif adalah sistem penyajian bahan pembelajaran yang ditampilkan dengan kontrol komputer dan direkam (visual, suara dan video) Pujiriyanto (2012), selain itu pengguna tidak sekedar melihat dan mendengarkan penyajian namun secara aktif merespon dan respon pengguna menentukan laju serta urutan penyajian. Kelebihan multimedia interaktif adalah menyajikan multisensori karena bersifat multimedia, ada partisipasi siswa, cocok untuk pembelajaran individual, fleksibilitas memilih menu, dan bias dipergunakan untuk simulasi.

Adapun penggunaan fitur mind map dalam media pembelajaran ini dirasa mampu untuk membantu siswa dalam meningkatkan daya ingatnya pada pembelajaran komputer dan jaringan dasar. Buzan (2013) menyatakan bahwa mind map adalah sebuah metode mencatat dimana catatan itu merupakan cara mengembangkan kegiatan berpikir ke segala arah, menangkap berbagai pikiran dalam berbagai sudut. Selanjutnya Buzan (2013) mengatakan mind map merupakan teknik yang paling baik dalam membantu proses berpikir otak secara teratur karena menggunakan teknik grafis yang berasal dari pemikiran manusia yang bermanfaat untuk menyediakan kunci-kunci universal sehingga membuka potensi otak. Adapun Sapoetra (2019) menyatakan mind map bertujuan membantu merekam, memperkuat, dan mengingat kembali informasi yang telah dipelajari dengan cara membuat materi pelajaran terpola secara visual dan grafis. Olehnya dengan mind map memberikan gambaran 
awal terhadap pemahaman materi yang akan dipelajari sehingga siswa menjadi lebih termotivasi serta mendorong kreativitas dan meningkatkan kecepatan berpikir (Buzan, 2010).

Penelitian ini bertujuan merancang media pembelajaran interaktif berbasis mind map yang menarik dan menyenangkan untuk digunakan sebagai sumber belajar.

\section{METODE PENELITIAN}

Penelitian dilaksanakan di SMK Negeri 5 Gorontalo, Provinsi Gorontalo. Penelitian dilakukan pada kelas x Teknik Komputer Jaringan (TKJ) pada mata pelajaran komputer dan jaringan dasar. Metode penelitian yang digunakan adalah Research and Development (R\&D) model pembelajaran ADDIE dengan tahapan adalah analisis, desain, pembangunan, implementasi, dan evaluasi (Branch, 2009; Aldoobie, 2015)

1. Tahap analisis: tahapan ini perlu diklarifikasi masalah standar kompetensi, kompetensi dasar, dan tujuan pembelajaran, serta lingkungan belajar, pengetahuan dan keterampilan siswa diidentifikasi.

2. Tahap desain: tahapan ini terdiri dari pemilihan materi yang relevan, kompetensi yang ingin dicapai, strategi pembelajaran, bentuk dan metode penilaian serta evaluasi difokuskan. Dalam hal ini perlu menetapkan verifikasi kinerja yang diinginkan dan metode pengujian yang sesuai.

3. Tahap pembangunan; kegiatan yang dilakukan pada tahapan ini adalah membuat contoh faktual untuk media pembelajaran; mengumpulkan sumber data yang relevan untuk memperkaya media pembelajaran; memvalidasi draft produk media dan revisi setelah revisi ahli akan dilakukan.

4. Tahap implementasi: pada tahapan ini hasil pengembangan diterapkan dalam proses pembelajaran untuk mengetahui pengaruhnya terhadap kualitas pembelajaran meliputi keefektifan, daya tarik, dan efisiensi. Tahap ini diujicobakan pada kelompok kecil untuk mendapatkan masukan untuk revisi draf produk.

5. Tahap evaluasi: tahapan ini menilai kualitas produk dan proses instruksional, baik sebelum maupun sesudah implementasi. Hasil penilaian ahli media, ahli materi dan pengguna (siswa) dapat menjadi masukan bagi pihak pengembang apakah kompetensi maupun media yang diharapkan tercapai dan layak untuk digunakan. Adapun prosedur penelitian ditunjukkan pada Gambar 1 di bawah.

Data yang digunakan dalam penelitian ini terdiri dari data kualitatif dan kuantitatif. Untuk data kualitatif berupa saran dan masukan berupa media dan perangkat pembelajaran (RPP dan LKS) terhadap media pembelajaran interaktif yang dibuat dari ahli media dan ahli materi. Data kuantitatif diperoleh dari uji kelayakan hasil oleh ahli materi dan ahli media dan pengguna terhadap media pembelajaran yang dibuat.
Adapun teknik pengumpulan data dilakukan melalui observasi, dokumentasi dan angket. Analisis data yang digunakan adalah analisis statistik deskriptif. Data yang diperoleh melalui angket oleh ahli media dan ahli materi dan pengguna (siswa dan guru) berupa nilai kuantitatif sesuai dengan aturan pemberian skor yang ada. Penilaian setiap aspek pada produk yang dikembangkan menggunakan skala likert seperti pada Tabel 1, dimana produk dapat dikatakan layak jika rata-rata dari setiap penilaian minimal mendapatkan kriteria baik.

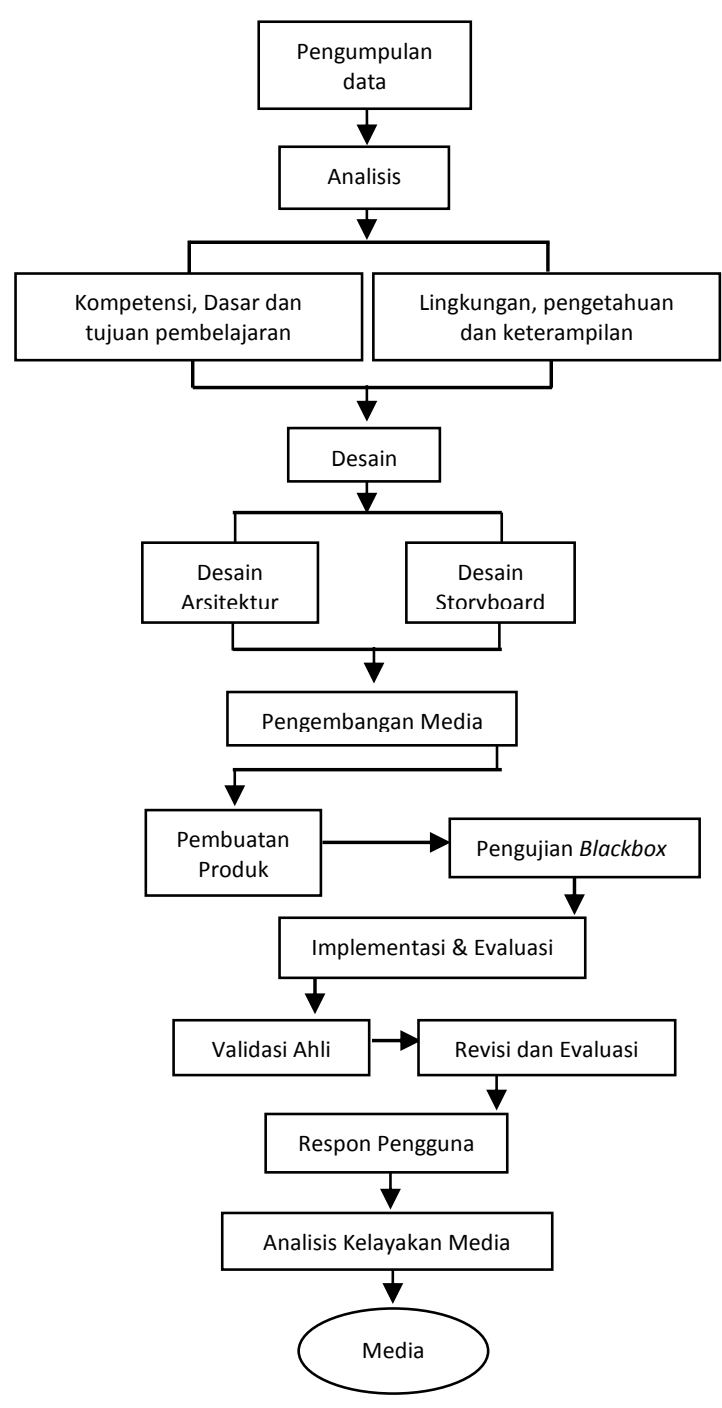

Gambar 1. Prosedur penelitian

Tabel 1

Skala likert

\begin{tabular}{lc}
\hline \multicolumn{1}{c}{ Kategori } & Skor \\
\hline Sangat Tidak Setuju (STS) & 1 \\
Tidak Setuju (TS) & 2 \\
Cukup Setuju (CS) & 3 \\
Setuju (S) & 4 \\
Sangat Setuju (SS) & 5 \\
\hline
\end{tabular}


Langkah-langkah dalam menganalisis data yang diperoleh menggunakan analisis deskiriptif adalah penilaian dengan kriteria yang telah ditentukan. Ketentuan konversi data kuantitatif menjadi kualitatif dan rentang skor penilaian ahli media, ahli materi dan pengguna (siswa dan guru) dapat dilihat pada Tabel 2. Data akan dikonversikan menjadi nilai dengan 5 skala yaitu 1, 2, 3, 4, dan 5 . Untuk mendapatkan besar persentase kelayakan media, secara matematis digunakan persamaan rating scale seperti berikut:

Presentase Kelayakan

$=\frac{\text { Jumlah Skor yang Diperoleh }}{\text { Jumlah Skor Ideal }} \times 100 \%$

Tabel 2

Skala interval kategori kelayakan (Arikunto, 2013)

\begin{tabular}{cc}
\hline Interval Presentase & Nilai \\
\hline$<21 \%$ & Sangat Tidak Layak \\
$21 \%-40 \%$ & Tidak Layak \\
$41 \%-60 \%$ & Cukup Layak \\
$61 \%-80 \%$ & Layak \\
$81 \%-100 \%$ & Sangat Layak \\
\hline
\end{tabular}

\section{HASIL DAN PEMBAHASAN}

Perancangan media pembelajaran interaktif berbasis mind map untuk mata pelajaran komputer dan jaringan dasar diawali dengan analisis kebutuhan materi, kebutuhan pengembangan (hardware dan software), dilanjutkan dengan perancangan desain arsitektur media dan perancangan desain storyboard. Pada tahap pembangunan, untuk aplikasi dikembangkan sesuai dengan desain arsitektur (flowchart) dan desain storyboard media pembelajaran,

Pembangunan media pembelajaran ini menggunakan perangkat lunak Adobe Photoshop sebagai pengolah gambar, dan Adobe flash CS3 sebagai perangkat lunak utama pembuatan media pembelajaran. Adobe flash CS3 dipilih karena memiliki fasilitas untuk menggabungkan grafis, audio, maupun animasi. Media pembelajaran dengan fitur mind map yang dikembangkan dalam penelitian ini menggunakan bahasa pemrograman Action Script 2.0 yang menghasilkan sebuah file utama berformat exe yang siap di unduh ke dalam sistem operasi

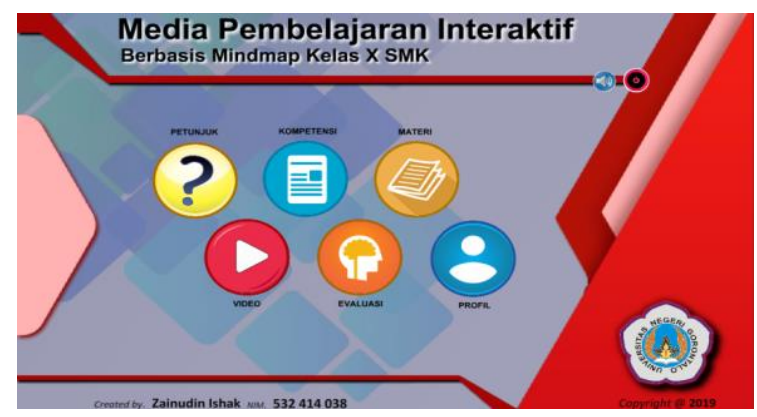

Windows. Secara umum, perancangan media pembelajaran ini meliputi:

Gambar 2. Tampilan menu Home

1. Pembuatan produk: desain antar muka (interface) disesuaikan dengan desain storyboard, untuk struktur setiap menu dan relasi antara menu (hyperlink) disusun berdasarkan flowchart.

Pada tampilan Gambar 2. berisi informasi menumenu yang ada pada media pembelajaran interaktif yang terdiri dari menu petunjuk, menu kompetensi, menu materi, menu video, menu evaluasi dan menu profil. Dimana setiap menu berisikan informasiinformasi yang dibutuhkan oleh pengguna untuk proses pembelajaran. Adapun Gambar 3. menunjukan halaman petunjuk yang dapat memudahkan pengguna dalam berinteraksi dengan media pembelajaran.

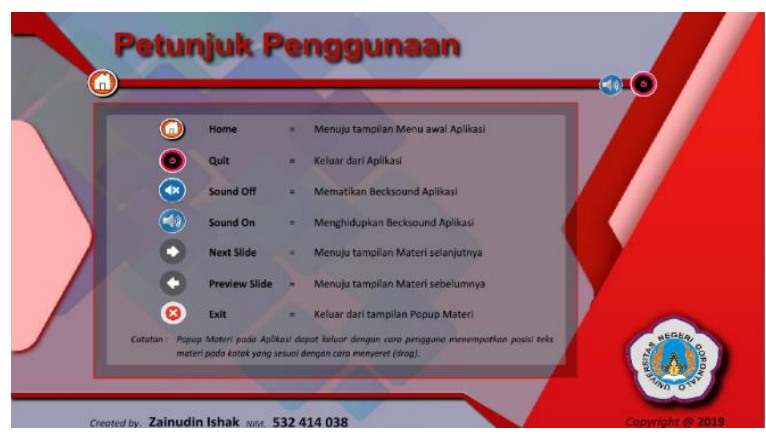

Gambar 3. Tampilan menu petunjuk

Pada Gambar 4 merupakan contoh materi yang disajikan, pengguna dapat memilih tombol materi yang disediakan, dan nantinya diarahkan menuju sub pokok materi sesuai dengan kompetensi dasar yang diajarkan.

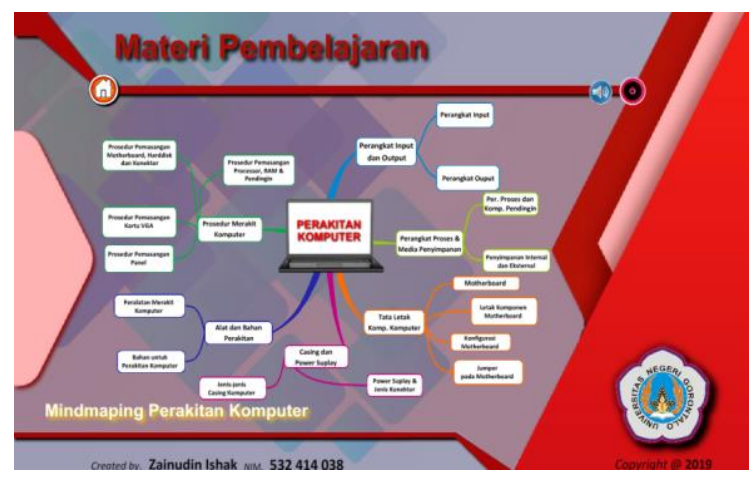

Gambar 4. Contoh tampilan menu materi

2. Publishing: proses pentransferan file extension (.fla) menjadi file adobe flash player, sehingga dapat di kompilasi ke dalam bentuk aplikasi exe agar dapat di unduh pada perangkat komputer.

3. Black box testing: pengujian menggunakan black Box Testing dan dilakukan dengan menjalankan aplikasi pada beberapa perangkat komputer dengan spesifikasi Operasional System (OS) yang berbeda-beda minimal menggunakan Windows 7 dengan beberapa kali pengulangan. Adapun hasil 
JTech 9(1), 1 - 6

uji fungsionalitas dari beberapa menu dapat dilihat pada Tabel 3 .

Tabel 3.

Hasil pengujian blackbox

\begin{tabular}{clcc}
\hline & & \multicolumn{2}{c}{ Hasil Pengujian } \\
\cline { 3 - 4 } No & \multicolumn{1}{c}{ Fungsi Navigasi } & Berfungsi & $\begin{array}{c}\text { Tidak } \\
\text { Berfungsi }\end{array}$ \\
\hline 1. & Fungsi Tombol Home & $\sqrt{ }$ \\
2. & Fungsi Tombol Petunjuk & $\sqrt{ }$ & \\
3. & Fungsi Tombol Kompetensi & $\sqrt{ }$ \\
4. & Fungsi Tombol Materi & $\sqrt{ }$ \\
6. & Fungsi Drag and Drop & $\sqrt{ }$ \\
7. & Fungsi Pop Up materi & $\sqrt{ }$ \\
8. & Fungsi Tombol Evaluasi & $\sqrt{ }$ \\
9. & Fungsi Tombol Profil & $\sqrt{ }$ \\
10. & Fungsi Tombol Sound & $\sqrt{ }$ \\
\hline
\end{tabular}

4. Implementasi: produk yang dibuat diterapkan dalam proses pembelajaran dan diujicobakan untuk mengetahui pengaruhnya terhadap kualitas pembelajaran. Hasil ujicoba berupa penilaian dari beberapa pengguna, selanjutnya dilakukan revisi untuk memperbaiki produk yang dikembangkan.

5. Evaluasi: hasil penilaian ahli media orang, ahli materi masing-masing sebanyak 2 orang dan pengguna (siswa) menjadi masukan bagi pihak pengembang agar media yang dihasilkan layak untuk digunakan.

Penilaian ahli materi berfungsi untuk menilai kebenaran, kesesuaian, dan kedalaman materi sehingga materi pada media pembelajaran sesuai dengan tujuan pembelajaran yang dicapai. Tabel 4. menunjukan hasil penilaian ahli materi.

Tabel 4

Hasil validasi ahli materi

\begin{tabular}{clccc}
\hline No & \multicolumn{1}{c}{ Aspek } & $\begin{array}{c}\text { Skor } \\
\text { valisasi }\end{array}$ & $\begin{array}{c}\text { Skor } \\
\text { diharapkan }\end{array}$ & $\begin{array}{c}\text { Persen } \\
(\%)\end{array}$ \\
\hline 1 & Isi Materi & 56 & 60 & $93 \%$ \\
2 & Sajian Materi & 40 & 40 & $100 \%$ \\
& Total & & & $96 \%$ \\
\hline
\end{tabular}

Uji penilaian ahli media meliputi fungsional dan usabilitas dan hasilnya ditunjukkan pada Tabel 5.

Tabel 5

Hasil validasi ahli media

\begin{tabular}{clccc}
\hline No & \multicolumn{1}{c}{ Aspek } & $\begin{array}{c}\text { Skor } \\
\text { divalidasi }\end{array}$ & $\begin{array}{c}\text { Skor } \\
\text { diharapkan }\end{array}$ & $\begin{array}{c}\text { Persen } \\
(\%)\end{array}$ \\
\hline 1 & Fungsional & 47.5 & 50 & $95 \%$ \\
2 & Usabilitas & 43.5 & 50 & $87 \%$ \\
& Total & & & $91 \%$ \\
\hline
\end{tabular}

Uji penilaian media pembelajaran interktif oleh pengguna sebanyak 30 orang diperoleh hasil seperti pada tabel 6 .
Suhada S, Ishak Z, Bahu K, Amali L.N, Rahmatin U.

Tabel 6

Hasil validasi pengguna

\begin{tabular}{clccc}
\hline No & \multicolumn{1}{c}{ Aspek } & $\begin{array}{c}\text { Skor } \\
\text { divalidasi }\end{array}$ & $\begin{array}{c}\text { Skor } \\
\text { diharapkan }\end{array}$ & $\begin{array}{c}\text { Persen } \\
(\%)\end{array}$ \\
\hline 1 & Penggunaan & 144.7 & 150 & $96.5 \%$ \\
2 & Usabilitas & 144.6 & 150 & $96.4 \%$ \\
& Total & & & $96,45 \%$ \\
\hline
\end{tabular}

Hasil penilaian ahli dan pengguna dikonversi kedalam bentuk penilaian untuk menentukan keefektifan produk yang dihasilkan berdasarkan presentase kategori kelayakan yang ditunjukkan pada Tabel 2. Berdasarkan Tabel 4 diperoleh hasil penilaian kelayakan ahli materi dengan presentase 96\% dan sesuai tabel kategori kelayakan dinyatakan "Sangat Layak" dan Gambar 5 menunjukkan pengelompokkan kategori berdasarkan validasi ahli media.

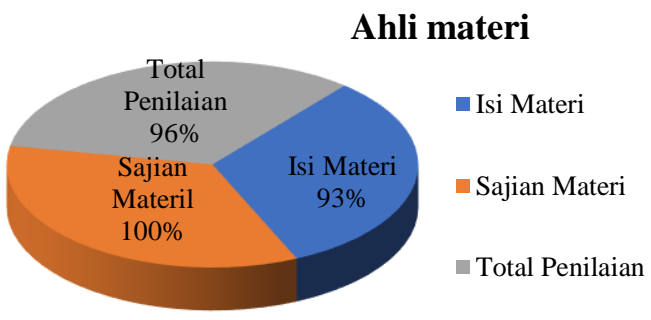

Gambar 5. Hasil validasi ahli meteri

Berdasarkan hasil tabel di atas diperoleh hasil penilaian kelayakan ahli media diperoleh presentase $89 \%$ untuk ahli media I dan $93 \%$ untuk ahli media II. Sehingga diperoleh hasil rata-rata penilaian kedua ahli media yaitu $91 \%$ dengan kategori "sangat layak". Untuk memperjelas pengelompokkan kategori pada validasi menurut ahli media dapat dilihat pada Gambar 6.

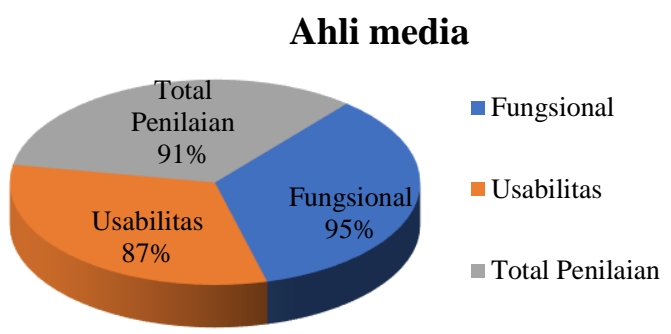

Gambar 6. Hasil validasi ahli media 


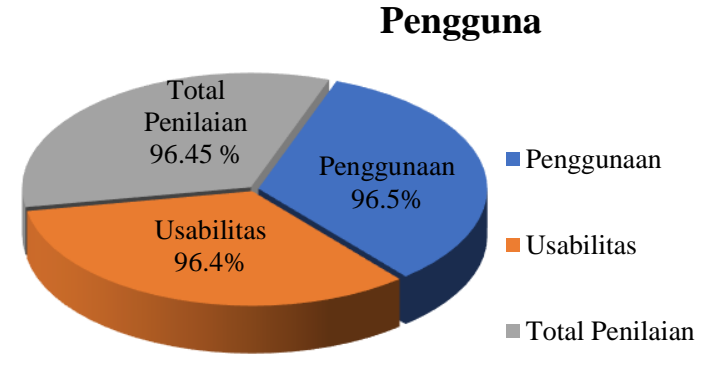

Gambar 7. Hasil validasi pengguna

Pada penilaian pengguna sebanyak 30 siswa diperoleh penilaian sebesar $96.5 \%$, nilai tersebut dapat dikategorikan pada kriteria sangat layak. Nilai tersebut dapat diinterpretasikan bahwa tingkat ketertarikan siswa pada media pembelajaran tergolong tinggi. Hal ini disebabkan karena metode mind map yang di integrasikan ke dalam aplikasi yang dikembangkan dapat memusatkan perhatian siswa karena mudah untuk di pahami sehingga dapat berkonsentrasi pada setiap pokok materi yang disajikan. Selain itu, penyajian materi yang mengusung tema drag and drop pada simulasi tampilan materi dari setiap sub pokok materi akan menambah daya ingat siswa terhadap materi yang disajikan, karena disajikan dalam bentuk game drag and drop. Hasil penilaian siswa pada aspek kebergunaan media pembelajaran memperoleh ratarata sebesar $96.4 \%$ dengan kriteria sangat layak. Untuk memperjelas pengelompokkan kategori pada validasi menurut pengguna dapat dilihat pada Gambar 7.

\section{KESIMPULAN DAN SARAN}

Media pembelajaran interaktif dengan fitur mind map menghasilkan produk berupa media pembelajaran yang berisi materi komputer dan jaringan dasar memiliki tingkat validitas kelayakan sangat tinggi sesuai penilaian para ahli media, ahli materi dan penilaian pengguna. Media pembelajaran yang dihasilkan sangat layak untuk di gunakan, dengan presentase kelayakan media pembelajaran menurut ahli materi sebesar 96\%, presentase kelayakan ahli media sebesar $91 \%$, serta penilaian pengguna $96.45 \%$. Dengan demikian media pembelajaran perakitan komputer dinyatakan layak untuk digunakan dalam kegiatan proses pembelajaran.

\section{UCAPAN TERIMA KASIH}

Terima kasih kepada Fakultas Teknik, Universitas Negeri Gorontalo atas dukungan dana penelitian kolaboratif PNBP BLU 2020.

\section{DAFTAR PUSTAKA}

Aldoobie, N. (2015). ADDIE Model. American International Journal of Contemporary Research, 5(6), 68-72.
Arsyad, Azhar. (2014). Media Pembelajaran. Jakarta: Rajawali Pers

Amali, L. N., Zees, N., \& Suhada, S. (2020). Motion graphic animation video as alternative learning media. Jambura Journal of Informatics, 2(1), 23-30.

Anggereni, S., \& Khairurradzikin. (2016). Efektivitas Pembelajaran Menggunakan Media Pembelajaran Macromedia Flash Dalam Meningkatkan Pemahaman Konsep Fisika Materi Hukum Newton. Jurnal Biotek, 4(2), 333-350.

Arikunto, S. (2013). Prosedur Penelitian Suatu Pendekatan Praktik. Edisi Revisi. Jakarta: PT. Rineka Cipta.

Branch, Robert Maribe. (2009). Instructional Design: ADDIE Approach. New York: Springer.

Buzan, T. (2010). Mind map for kids: An Introductions. Thorsons: Reissue edition.

Buzan, Tony. (2013). Mind Map Untuk Meningkatkan Kreativitas. Jakarta: Gramedia Pustaka Utama.

Eady, M. J. (2013). Tools for learning: technology and teaching strategies, learning to teach in the primary school. Queensland University of Technology: Australia. 71.

Gagne, R. M. (1985). The Conditions of Learning and Theory of Instruction. New York: Holt Rinehart and Winstone.

Pujiriyanto. (2012). Teknologi untuk Pengembangan Media dan Pembelajaran. Yogyakarta: UNY Press.

Pramuaji, A \& Munir, M. (2017). Pengembangan Media Pembelajaran Interaktif Pada Materi Pengenalan Corel Draw Sebagai Sarana Pembelajaran Desain Grafis Di Smk Muhammadiyah 2 Klaten Utara. Elinvo (Electronics, Informatics, and Vocational Education), 2(2), 183-189.

Rusman. (2013). Belajar dan Pembelajaran Berbasis Komputer. Bandung: Alfabeta.

Sadiman, Arif S. (2014). Media Pendidikan Pengertian, Pengembangan, dan Pemanfaatannya. Jakarta: Raja Grafindo Persada.

Saputra, A., (2013), Membangun Aplikasi bioskop dan sms untuk panduan skripsi. Jakarta: Elex Media Komputindo.

Sapoetra, B. P. (2019). Efektifitas Penerapan Mind Mapping Dalam Meningkatkan Hasil Belajar IPA Pada Peserta Didik Sekolah Dasar. Else (Elementary School Education Journal), 3(2), 87-97.

Suryani N. (2016). Pengembangan Media Pembelajaran Sejarah Berbasis It. Sejarah dan Budaya, (10)2, 186-196.

Suryani, N. (2017). Pengembangan Media Pembelajaran Berbasis IT. Prosiding Seminar Nasional Teknologi Pendidikan. 1-13. 